\title{
Conhecimento Social Emergente e Conhecimento Glocal
}

\section{Emerging Social Knowledge and Glocal knowledge}

\author{
Elizeth Gonzaga dos Santos Lima* \\ Denise Leite ${ }^{* *}$
}

\begin{abstract}
RESUMO
Os impactos do viés neoliberal sob o comando do mercado e controle do Estado tem se manifestado nas ações diárias da vida docente e do pesquisador universitário. O sujeito que produz o conhecimento está sendo desqualificado frente às políticas de avaliação, contudo sua prática se insere nas comunidades locais e estas ações nem sempre se tornam visíveis. O objetivo desse estudo foi analisar o que está sendo posto como verdade para a universidade, desvelando outras instâncias pouco conhecidas, como o são aquelas das ações com pertinência local/regional. A metodologia qualitativa incluiu estudos de caso sobre as produções docentes do Programa de Pós-Graduação em Educação Unemat, Brasil. As ações que acontecem nos diferentes campi da universidade, e resultam em publicações, foram mapeadas segundo os territórios em que ocorrem. Mostraram saberes, percepções e ações, invisíveis às avaliações. Evidenciou-se que a ações fortalecem a regionalização e têm efeitos sobre sujeitos e contextos locais. São ações que ainda não são captadas por indicadores e critérios de avaliação das medidas de larga escala que incidem sobre os programas de pós-graduação e a pesquisa. De tais ações, contra-hegemônicas, resulta um 'conhecimento social emergente'. Propomos neste texto que o conhecimento local-regional, o conhecimento social emergente, também pode ser internacionalizado, tornando-se conhecimento Glocal, sendo local, regional e global ao mesmo tempo.
\end{abstract}

Palavras-chave: Conhecimento social emergente. Pós-Graduação. Avaliação. Conhecimento Glocal.

*Universidade Estadual do Mato Grosso. Cáceres, Mato Grosso, Brasil. E-mail: elizeth@ unemat.br. http://orcid.org/0000-0002-3340-5587.

${ }^{* *}$ Universidade Estadual do Mato Grosso. Cáceres, Mato Grosso, Brasil. E-mail: denise. leite@pq.cnpq.br. http://orcid.org/0000-0002-9855-572X. 


\begin{abstract}
The impacts of the neoliberal bias under the command of the market and control of the State have been manifested in the daily actions of the university teaching and researching. The knowledge-producing subject is being disqualified from quantitative politics imposed by the evaluation policies however their practice effectively falls within the local communities and these actions do not always become visible. The objective of this study was to analyze what is being considered as truth for the university, unveiling other instances of its action, little known as are those actions with local/regional relevance. The methodology used was qualitative research, case study, in which the locus and corpus of analyzes were the research productions of the Post-Graduation Program in Education Unemat, Brazil. The actions captured, invisible to the evaluations, show knowledge, perceptions and actions that happen in the different campuses of the university. They were mapped according to the territories in which they occur. Such actions strengthen regionalization and they have effects on local subjects and contexts. These actions are not yet captured by indicators and evaluation criteria of the large-scale measures that affect graduate programs and research. From such counter-hegemonic actions results an 'emerging social knowledge'. We bring to this text the evidence that local-regional knowledge, Emerging Social Knowledge, can also be internationalized by becoming Glocal Knowledge, being local, regional and global at the same time.
\end{abstract}

Keywords: Emerging social knowledge. Postgraduate studies. Evaluation. Glocal Knowledge.

\title{
Introdução
}

Este estudo emergiu nas discussões realizadas pelo grupo de estudos e pesquisas em avaliação educacional (Gepave/Unemat) com o desenvolvimento do Projeto de pesquisa 'Avaliação, regionalização e internacionalização da educação superior: ações na Unemat' e na disciplina 'Internacionalização da universidade e suas relações com a avaliação', tendo como colaboradores da pesquisa mestrandos da disciplina e participantes do Gepave. Essas e outras experiências que vivenciamos como pesquisadoras de Programas de Pós-Graduação nos levaram a questionar a produção do conhecimento que aparece nas avaliações - aquele que está documentado nas publicações - e pensar que o docente como sujeito que produz esse conhecimento publicado, faz bem mais do que aparece. Como estamos produzindo? O que estamos efetivamente fazendo no âmbito local e 
regional e em que tempo? Com que qualidade? Foram questões que fomentaram o debate e deram origem a esse artigo.

Observamos que o sujeito do conhecimento está sendo desqualificado frente ao quantitativismo imposto pelas políticas de avaliação, porém sua prática efetivamente se insere nas comunidades locais e estas ações nem sempre se tornam visíveis. Essas e outras questões relacionadas à produção do conhecimento nas universidades nos incomodam e nos movem a estudá-las, a fim de compreendê-las.

A nosso ver, a avaliação está a carregar implicitamente uma concepção de educação que serve ao desenvolvimento e consolidação dos princípios neoliberais: produtividade, liberdade de escolha; produzir mais em menos tempo e menor custo. Nesse sentido, a produção do conhecimento está a ser afetada pelas políticas educacionais, nacionais atravessadas pelas agendas internacionais (AKKARI, 2011), que define os parâmetros de qualidade e utilizam a avaliação como princípio, meio e fim para garantir que o conhecimento seja produzido nesses valores. Assim, nos parece essencial pensarmos a função social da universidade e a qualidade do que está sendo produzido e disseminado verdadeiramente pelas práticas de docentes/pesquisadores no nível local e regional em contraposição àquilo que lhe é exigido no nível nacional/internacional de suas publicações.

Como sabemos, os impactos do viés neoliberal, o aumento da produtividade sob o comando do mercado e controle do Estado, têm se manifestado nas ações diárias da vida docente e dos pesquisadores da universidade. Como docentes da Educação Superior nos níveis da graduação e da pós-graduação temos sentido cotidianamente a precarização do trabalho em nome de uma questionável e pretensa qualidade. Com um regime de trabalho exclusivo para a universidade e uma pressão produtivista, manifestada pelos parâmetros de qualidades definidos pelas Políticas Educacionais e controlados pela Avaliação, nossas atividades acadêmicas estão se resumindo ao quantitativismo, a preenchimento de tabelas e plataformas avaliativas de produção docente.

Nas reuniões de docentes, por exemplo, no interior dos Programas de Pós-graduação e nas discussões externas que emergem nos fóruns e encontros de educação, o que temos observado é uma preocupação em atingir as metas propostas pelas políticas, bem como alcançar indicadores e parâmetros definidos pelas políticas de avaliação. Entre os docentes, observamos um mal-estar, que se por um lado resulta da pressão, pois discordam de tais políticas, por outro, não vêm alternativas a não ser entrar no jogo e se adequar às regras para se manterem, do contrário, estarão fora do jogo. Nosso estudo nos remete a pensar alternativas contra-hegemônicas, pois ainda acreditamos na implantação da avaliação como possibilidade de instaurar nos espaços da universidade e 
nas atitudes dos sujeitos os princípios da emancipação, mesmo em tempos de globalização. Para tanto, o objetivo foi analisar crítica e abertamente o que está sendo posto como verdade para a universidade, desvelando outras instâncias de sua ação, instâncias pouco conhecidas como o são aquelas das ações com pertinência local/regional.

A metodologia utilizada foi a perspectiva da pesquisa qualitativa, por meio do estudo de caso, no qual o locus e corpus de análise foram as produções dos docentes do Programa de Pós-Graduação em Educação da Unemat, descrevendo as práticas das pesquisas, objetos estudados, relevância social/local, resultados e impactos. Com a colaboração dos mestrandos e participantes do grupo de pesquisa, o primeiro momento do estudo consistiu em mapear as pesquisas e as produções e selecionar àquelas com maior relevância social, regional e local. No segundo momento se analisou os veículos de publicação dessas produções e ações realizadas localmente pelos docentes/pesquisadores, a fim de verificar se essas produções estavam classificadas no Qualis/Capes. Analisaram-se as produções selecionadas, utilizando o conceito Glocal para aprofundar a avaliação, a regionalização e a internacionalização da educação superior.

\section{Concepções Teóricas e Práticas da Internacionalização/Regiona- lização}

Neste estudo partimos de dois processos que marcam as universidades contemporâneas - a internacionalização e a avaliação. Quando falamos internacionalização parece que enfatizamos a mobilidade docente ou discente, a mais conhecida estratégia. Porém, estamos a nos referir às tendências de globalização da educação superior, às relações universitárias para além do estado-nação; aos valores que levam à uma identificação com o capitalismo acadêmico, aquele que bem conhecemos como produto das avaliações que incidem sobre o produtivismo e o necessário empreendimento individualizado, uma tendência global de mercantilização do conhecimento independente da área de conhecimento (EDWARDS \& ROY, 2017). Estamos falando também da chamada "livre corrente de ideias, capitais, pessoas e bens ao redor do mundo" e da hegemonia capitalista com possível perda de identidades e culturas nacionais (MARGINSON \& RHOADES, 2002; MOROSINI, 2006).

O produtivismo está presente na "correria" da vida acadêmica, como consequência, falta oportunidade e tempo para refletir, pensar, estudar. Sofremos para atender os padrões exigidos, a dificuldade para publicar em periódicos 
com classificação alta em Qualis/Capes e internacionais (LIMA et al., 2016), pois estes são considerados como os principais indexadores de qualidade da pós-graduação.

Nesse contexto, é preciso buscar alternativas qualitativas que valorizem a regionalização da produção do conhecimento para além de apenas nos submeter ao controle internacional da ciência. Chaimovich (2016), ex-presidente do CNPq, falou sobre a importância de mudar a maneira de avaliar a qualidade da ciência, muito focada em números e resultados, quando se deveria pensar no impacto que esse conhecimento deve ter na sociedade. Ainda acrescentou que a ciência deve gerar impacto intelectual, social e econômico. Inserir esses indicadores na avaliação da produção do conhecimento faz-se necessário para potencializar o conhecimento produzido na universidade como um bem comum que traga à sociedade qualidade de vida e realização social dos sujeitos que produzem.

Por impacto intelectual, Chaimovich (2016) descreve as ideias que produzem novas ideias, que fazem a humanidade mais sábia e que permitem formar gerações de novas ideias. Já o impacto social está relacionado ao conhecimento produzido capaz de influenciar políticas públicas, que possa diminuir a desigualdade, ou mesmo que possa reduzir, por exemplo, o tempo de espera na fila do SUS; ou, ainda, que aumente o envolvimento social com a ciência. Por fim, o impacto econômico corresponderia às ideias que criam empresas e geram empregos, que aumentam a competitividade e criam setores industriais. "Não podemos só prometer, temos que mostrar o impacto de tudo que já fizemos", alerta o ex-presidente, sobre a importância de se avaliar estrategicamente os projetos de pesquisa, pensando justamente em como eles vão gerar impacto na sociedade.

Ora, a educação trabalha a longo prazo, seus impactos serão vistos após o completamento da formação dos alunos e dos novos professores, o que pode levar décadas de esforço e compromisso para caracterizar um impacto econômico, social e intelectual. Contudo, os docentes da educação, no curto prazo, não trabalham apenas com o impacto intelectual sobre o aluno, eles agem diretamente sobre as comunidades em uma ação que envolve práticas pedagógicas e políticas de curto e médio alcance. Tais ações fortalecem a regionalização, têm efeitos sobre sujeitos e contextos locais. São ações que não resultam em indicadores de avaliação para medida imediata, que atendam a critérios da Capes ou do Qualis.

Entendemos por regionalização da produção do conhecimento a construção coletiva de um saber que permita enfrentar criticamente os desafios colocados às sociedades nesta fase da economia globalizada. Nesse sentido, as construções coletivas da produção do conhecimento regional pressupõem 
que os pesquisadores e suas instituições passem a pensar-se a si próprios fora dos limites nacionais e assumam enfoques transnacionais, dizem Krawckzik e Sandoval (2012, p. 663) ao alertar sobre o momento vivido pelas universidades. Nas entrevistas que realizaram, os autores dizem que os informantes identificaram a regionalização da universidade como sinônimo de internacionalização.

Estamos a viver intensamente na universidade os processos de avaliação e internacionalização com as suas consequências e, via de regra, encontram-se estudos de internacionalização sob a forma de críticas à globalização. Dale (2004), por exemplo, aponta a internacionalização das instituições de educação superior como uma pretensão hegemônica dos países centrais. Segundo o autor Roger Dale (2004), a internacionalização adquire duas formas principais, uma delas seria intitulada (CEMC) e a outra, Agenda Global Estruturada para a Educação (AGEE). A CEMC defende que a universidade e os sistemas de educação superior sempre foram internacionalizados; desde sempre se trabalhou, por exemplo, com categorias curriculares semelhantes e modelos universais de Educação. De certa forma, os modelos não seriam puramente nacionais, pois, de alguma maneira, seriam cópias e reproduções de outros existentes em diferentes países que viriam a ser multiplicados internacionalmente. Particularmente poderíamos denominar este modelo como 'Modelo Ctrl C, Ctrl V', porque a formação de um médico, advogado, dentista, agrônomo, professor seria a mesma na Europa, América, Ásia. Nessa perspectiva haveria uma qualidade universal que dispensaria, inclusive, as avaliações e acreditações.

$\mathrm{Na}$ outra abordagem de Dale (2004), entraria a AGEE, Agenda Global Estruturada para a Educação, na qual, diz ele, a globalização mostraria suas forças, a imposição de modelos de controle de qualidade. O processo seria contraditório porque as economias dos chamados países desenvolvidos competem com as economias daqueles em desenvolvimento e emergentes. A educação superior seria um negócio e a qualidade valorizaria o bem no mercado. A "abordagem AGEE vê o capitalismo como a força causal, conduzida pela procura do lucro" (DALE, 2004, p. 438). De qualquer sorte, as duas abordagens justificam a procura de qualidade através da internacionalização. São posições que poderiam explicar os movimentos em prol das avaliações e acreditações internacionais, em favor das competências curriculares e do processo de Bolonha transplantado para a América Latina. A posição AGEE poderia estar na base das ações de agências como BM, Banco Mundial, através da GIQAC (Global Initiative for the Capacity of Quality Assurance), do Banco Santander, através do conhecido Universia, e seus múltiplos programas de financiamento de mobilidade e projetos universitários, da OCDE (Organização para a Cooperação e Desenvolvimento Econômico), da Comunidade Europeia e seus programas de integração com América Latina e Caribe (LEITE \& GEN- 
RO, 2012). Ou seja, a força das agências hegemônicas do capitalismo global estaria a influenciar os sistemas de educação superior nacionais, a valorizar a importância da internacionalização e da avaliação.

Percebemos que essas pressões que emergem de modelos impostos pela ordem mundial capitalista têm levado pessoas que fazem a universidade e constroem um projeto de educação superior a cederem às pressões, tanto da sociedade como do Estado, e voltar suas atividades de pesquisa muito mais para atender uma demanda de mercado do que para a transformação social, transformando o conhecimento em mercadoria. Dessa forma, o projeto de universidade passa a se redesenhar e a sustentar na ética utilitarista. Nesse amálgama a produção do conhecimento se encerra em um conflito. O conflito está posto quando a universidade tenta fugir do redesenho, voltar-se para as comunidades, regionalizar-se, tratar de incluir os des-incluídos, redesenhar o seu papel, investindo na função de produzir conhecimento para a transformação da sociedade local. Porém, há um reduzido referencial sobre regionalização e conhecimento social emergente.

Este foi o objetivo da pesquisa que desenvolvemos - enfrentar crítica e abertamente o que está sendo posto como verdade para a universidade, desvelando outras instâncias de sua ação, instâncias pouco conhecidas como o são aquelas das ações com pertinência local/regional. Para Milton Santos (2006), estas ações levadas a cabo na horizontalidade são um espaço da interação emergente, no qual se vai produzir o conhecimento. A verticalidade, seria o ponto de codificação para uma integração à epistemologia do Global e, na articulação de horizontalidades e verticalidades emergiria, no ponto de encontro entre os eixos, a Glocalização.

\section{Produção do conhecimento local regional com qualidade}

\section{O contexto}

As características da produção científica dos docentes da Unemat aqui relatadas são consequências de uma trajetória cultural e histórica que acompanhou o processo de expansão da universidade, tendo como princípio o atendimento aos interesses do interior do país, das regiões menos desenvolvidas e a necessidade de atendimento a essas regiões desassistidas pela educação superior.

A Universidade do Estado de Mato Grosso (Unemat) foi criada em 1978 com o objetivo de atender a qualificação e formação de professores. Desde a sua 
criação vem adotando diferentes e inovadoras formas de ofertar a graduação. A expansão da Unemat ${ }^{1}$ ocorreu com uma perspectiva de ser uma Universidade 'do interior para o interior' e com o objetivo de atender a uma população que está geograficamente sem acesso aos centros de educação superior. Essa expansão guarda características regionais e locais levando a instituição a se democratizar ao longo dos anos numa perspectiva que valoriza a inclusão social. Assim, analisamos algumas produções e temáticas de pesquisa dos docentes do PPGEdu/ Unemat, as quais constroem a identidade do Programa (e da universidade), e as consideramos como experiências emergentes no contexto local/regional das comunidades, o que caracterizaria a forma que a instituição, histórica e culturalmente, vem construindo. Caracterizaria a sua função social, a função que a identifica como uma importante universidade para a sociedade do interior do país e da América Latina.

\section{Pesquisas e ações no contexto}

Neste texto trazemos um resumo, pequenos excertos das pesquisas e ações e das publicações que as documentam e foram analisadas na pesquisa. Destacamos dentre outras, as ações que caracterizam Economia solidária, Educação do Campo e Movimentos sociais do Campo, Qualificação docente em serviço, Educação indígena e Espaço pantaneiro - criança ribeirinha.

\section{Economia solidária ${ }^{2}$}

Práticas agroecológicas dos empreendimentos econômicos solidários (EES) da comunidade Che Guevara no Assentamento Antônio Conselheiro Tangará da Serra-MT - O objetivo deste projeto foi identificar e caracterizar as práticas agroecológicas utilizadas no assentamento. Além disso, o projeto

1 Atualmente, a IES oferta, na graduação, 60 cursos na modalidade presencial de oferta contínua, 19 cursos de graduação na modalidade parceladas, 04 vinculados ao Parfor presencial, 06 turmas fora de sede, 02 cursos vinculados à Faculdade Intercultural Indígena e 12 cursos à distância. Na pós-graduação Lato Sensu são 08 cursos ofertados à distância, 05 presenciais e 01 pela Faculdade Intercultural Indígena. Na pós-graduação Stricto Sensu temos 11 cursos de mestrado institucional, 03 cursos de mestrado profissional, 04 cursos de doutorado institucional, 03 doutorados em rede $\mathrm{e}$ 04 doutorados interinstitucionais. Em 2017, a Unemat possui 13 campus, 12 núcleos pedagógicos, 24 polos de ensino à distância e atende uma demanda de cerca de 22.000 estudantes.

2 SGUAREZI, S. B.; DUARTE, W. M.; GAZONI, E. G. Práticas agroecológicas dos empreendimentos econômicos solidários (EES) da comunidade Che Guevara no Assentamento Antônio Conselheiro - Tangará da Serra-MT. In: ZART, L. L; VAILANT, Clovis (Org.). Educação e socioeconomia solidária: configurações do campo e experiências educacionais . Série sociedade solidária. Cáceres: Unemat, 2015, v. 7, p. 98-104. 
visa identificar demandas de pesquisa e extensão na comunidade e iniciativas socioprodutivas pelo viés da autogestão. Essa pesquisa produziu conhecimento sobre a Agricultura Familiar, o Agro ecossistema como sendo as alterações feitas pelo homem no ecossistema natural em um ambiente superprodutivo. A Agroecologia e Desenvolvimento Rural Sustentável que tem como finalidade substituir as práticas agressivas ao meio ambiente e não ecológicas, por práticas que visam maior preservação e conservação do ecossistema. AAutogestão como sendo um projeto de organização democrática que privilegia a democracia direta e sobre a Juventude Camponesa, analisando a permanência e não permanência do jovem no campo. Os resultados desse estudo apontam que a falta de renda, juntamente com falta de apoio governamental e falta de formação superior dos jovens e das famílias de assentados tem sido problemas bastante graves dentro do assentamento, que reflete principalmente no favorecimento do êxodo rural. Segundo o relato da própria juventude, quando os jovens chegavam em uma certa idade, eles acabavam se mudando do assentamento por falta de renda, por falta de formação superior e ainda por falta de oportunidade.

\section{Educação do campo - Movimentos sociais do campo $^{3}$}

Estudo 1 - O processo de construção de conhecimentos: o diálogo entre a universidade e os movimentos sociais do campo na experiência do Camosc. - Esse estudo teve como objetivo compreender, no processo de interação da universidade e dos Movimentos Sociais do Campo, as possibilidades da produção social do conhecimento. Com base nos conceitos de pesquisa-ação e ecologia dos saberes investigou-se a interrelação e a dialogicidade entre saberes distintos, o científico e o saber da experiência camponesa, na constituição de ambiências que traduzem epistemologias adequadas para as relações societais camponesas. Produziu-se conhecimentos sobre o desenvolvimento das UPAS (Planejamentos das Unidades de Produção Agroecológica e de Socioeconomia Solidária); o sujeito como produtor do conhecimento; Saberes dos camponeses e os conhecimentos codificados da ciência - pedagogia da alternância (TE - tempo na escola e TC - tempo na comunidade); a agroecologia e a socioeconomia solidária.

Estudo $2^{4}$ - Artigo "Relação Trabalho-Educação em Escolas do Campo" - esse artigo evidencia a relevância do trabalho social que essa docente perma-

3 ZART. Laudemir Luiz; BITENCOURT, Loriége Pessoa. O processo de construção de conhecimentos: o diálogo entre a universidade e os movimentos sociais do campo na experiência do CAMOSC. In: ZART. L. L.; VAILANT, C. (Org.). Configurações do Campo e Experiências Educacionais. 1ed. Editora UNEMAT, 2015, v. 1, p. 127-133.

4 MACHADO, Ilma Ferreiro, Relação Trabalho-Educação Em Escolas do Campo. In: Livro da Anped-CO, Vol I, 2012. 
nente do PPGEdu/Unemat vem desenvolvendo. A Professora relata que sua pesquisa de doutorado ocorreu no Assentamento (do MST) Nova Conquista, a $60 \mathrm{~km}$ de Cáceres, e resultou na Tese "Organização do trabalho pedagógico em uma escola do MST e a perspectiva de formação omnilateral”. Resultados do doutorado levou-a a dar continuidade e desenvolver projetos de pesquisa nas escolas do campo em assentamentos do MST. As pesquisas tiveram interfaces com a extensão e são desenvolvidas coletivamente com orientandos de mestrado, iniciação científica e professores da educação básica que trabalham nas escolas do MST. A docente foi uma das articuladoras junto a Secretaria Municipal de Educação da I Conferência municipal de educação do campo no Município de Cáceres, na qual foram formuladas/aprovadas propostas para o Plano Municipal de Educação, sobre a educação do campo.

\section{Qualificação docente em serviço (módulos e etapas) ${ }^{5}$}

Esse estudo discute o processo de expansão e democratização da Unemat, analisando o acesso e a permanência dos estudantes. A trajetória expansionista da Unemat foi marcada por diferentes formas de promover o acesso à educação superior de comunidades e populações específicas, além de ofertar vagas em demanda de ampla concorrência. Exemplificando essa diversidade, citamos a criação, em 1992, de um Projeto denominado "Licenciaturas Plenas Parceladas" como oferta de formação em rede, em serviço e continuada denominado. Uma proposta de integração entre ensino e pesquisa, surgido na região do Médio Araguaia, por ocasião da criação do Campus de Luciara, distante há mais de mil quilômetros da sede da Unemat. O projeto é conveniado com Prefeituras Municipais e executado nos meses de férias escolares dos professores, adotando uma proposta pedagógica de inserção da formação teórica nas práticas educativas das escolas (MEDEIROS, 2008, p. 12). Na mesma linha de atuação também foram criados o Programa Módulos Temáticos (2001) e o Programa Institucional de Qualificação Docente (2003). Desde 1999, a Unemat oferta cursos de graduação a distância e em 2008 passou a integrar o sistema Universidade Aberta do Brasil (UAB/Capes/MEC). Em 2001, teve início o Projeto de Formação de Professores Indígenas $-3^{\circ}$ Grau Indígena, com vista à formação em serviço e

5 LIMA, Elizeth Gonzaga dos Santos; MALANGE, Fernando Cezar Vieira; BARBOSA, Valci Aparecida Barbosa. Políticas de Expansão da Educação Superior Implantadas Pelo Estado Brasileiro: Reflexões Sobre Democratização: o caso da Unemat. In: Expansão privado-mercantil da educação superior no Brasil / Vera Lúcia Jacob Chaves, Olgaíses Cabral Maués, Salomão Mufarrej Hage, (organizadores). Campinas, SP: Mercado de Letras, 2016. -- (Série educação geral, Educação superior e formação continuada do educador). 
continuada de professores e profissionais indígenas e a abertura de vagas nos cursos regulares de pós-graduação lato e stricto sensu. Ainda, com vista a atender às reivindicações da sociedade, a Unemat ofertou, no ano de 2003, o curso de Pedagogia aos educadores da reforma agrária (CPERA), e em 2005, o curso de Agronomia para os movimentos sociais do campo (CAMOSC). As diferentes formas de ingresso implantadas pela Unemat, que atingem a todas as camadas sociais, nos levam a afirmar que sua expansão teve como foco a democratização e que sua história comprova que, em relação ao ingresso, a IES vem cumprindo sua missão de ser democrática.

\section{Educação Indigena ${ }^{6}$}

O estudo Projeto Ação Saberes Indígenas na Escola tem como objetivo a produção de materiais didáticos-pedagógicos pelos professores indígenas juntamente com seus alunos sob orientação dos autores. Nesse sentido, foram produzido cinco livros bilíngues para servirem de material de apoio nas aulas das aldeias, sendo: Terena/Português; Kayapol/Português; Kayabi/Português; Munduruku/Português; Apiaka/Português. Os livros já estão sendo utilizados nas escolas indígenas sob orientação dos autores (ZOIA, 2018).

\section{Espaço pantaneiro: criança ribeirinha ${ }^{7}$}

Esse estudo apresenta narrativas do espaço pantaneiro e da experiência coletiva de crianças que moram na Campina, região labiríntica do Pantanal mato-grossense. Apresenta a força interpeladora de narrativas incompletas que podem esfacelar a rigidez que ainda persiste no tempo presente no campo educacional. Essas narrativas tem a intenção de criar um novo espaço, uma nova história para a criança que ganhou a característica de frágil, desprotegida, incompleta pela narrativa dominante. É com base na experiência de um ano da autora passado na Campina, vivendo, convivendo, conversando, observando, brincando, anotando, ouvindo, gravando, aprendendo, fotografando, cartografando, que

6 ZOIA, A.; ARAUJO, A. E. . Mebêngõkre Kabêm: Língua do povo do buraco da água. 1. ed. Sinop: Gráfica Dados, 2018. v. 200. 60p. - ZOIA, A.; ARAUJO, A. E. . Mini Dicionário Terena MT. 1. ed. Sinop: Gráfica Dados, 2018. v. 200. 71p. - ZOIA, A.; FERREIRA, W. A. A. . Dicionário Ilustrado Apiaká. 1. ed. Sinop: Gráfica Dados, 2018. v. 200. 68p. - ZOIA, A.; FERREIRA, W. A. A. . Cartilha Kawaiwete. 1. ed. Sinop: Gráfica Dados, 2018. v. 200. 54p. ZOIA, A.; NASCIMENTO, R. ; FERREIRA, W. A. A. . Saberes Indígenas na Escola: Frutas Silvestres. 1. ed. Sinop: Gráfica Dados, 2018. v. 200. 70p.

7 MALDONADO, Maritza Maciel Castrillon. Espaço pantaneiro: cenário de subjetivação da criança ribeirinha. Curitiba: CRV, 2017. 
essas narrativas são apresentadas como possibilidades reais de experiências educativas coletivas no mundo atual. $O$ espaço pantaneiro é concebido como uma narrativa constituidora do processo de subjetivação da criança ribeirinha que foge à regra da subjetividade requerida e/ou produzida na/pela modernidade. Considera crianças da Campina com experiências que resistem ao saber e ao poder, experiências ímpares que, no seu limite, talvez, possam produzir algo novo, que seja diferente do sujeito individual requerido pelo projeto moderno.

Evidenciamos nos estudos selecionados para esta pesquisa, em nossas análises, que o conhecimento produzido tem caráter social, sendo emergente, potencializado na relevância social e local. Tal conhecimento produzido, no entanto, não está publicado em revistas classificadas com Qualis/Capes ou nas revistas internacionais com fator de impacto reconhecido pelas avaliações vigentes. A maioria dos estudos está publicada em livros de circulação local/regional e que não vêm sendo considerados pelos indicadores avaliativos. Por este motivo se torna um conhecimento invisibilizado. Ao mesmo tempo, os livros, dissertações, capítulos e teses parecem não estar sendo valorizados ou têm pouco reconhecimento nas classificações avaliativas da Capes. No entanto, o conhecimento produzido analisado provém de problemas do meio e interessa ao meio em que se insere a universidade, é relevante e pode produzir a transformação social no contexto local/regional e, portanto, é um conhecimento emergente e precisa ser reconhecido, precisa sair do silêncio e da invisibilidade. As produções analisadas e, excertos acima, mostram que os docentes voltaram seu olhar para:

Questões e problemas locais e regionais;

Realizaram pesquisas in loco com populações diferenciadas;

Ofereceram formação a populações que estavam à margem do desenvolvimento cultural, regional, social, tecnológico;

Levaram ensino superior de qualidade a populações des-incluídas;

Realizaram ações educativas com populações marginalizadas pelas políticas hegemônicas;

Captaram saberes e conhecimentos antes des-conhecidos.

Enquanto, por sua vez, a universidade voltou suas ações para:

Alavancar as regiões periféricas de Mato Grosso no seu processo de democratização do acesso à educação superior;

Inseriu-se em comunidades de povos originais;

Atingiu municípios e comunidades cujo acesso somente é possível por meios pouco convencionais de transportes (transporte fluvial e trajetos de longa distância do município sede da universidade);

Acolheu populações que estavam às margens do sistema da educação superior.

Nesse sentido, entendemos que o conhecimento produzido é emergente, 
é social, é plural e não emerge de uma ordem global internacional, de políticas governamentais, de editais de agências de fomento/financiamento. Contudo, nem sempre os estudos resultantes das investigações encontraram acolhida em revistas de prestígio ou os artigos publicados em periódicos Qualis/Capes, por uma simples razão - este conhecimento produzido emerge de contextos e demandas locais, da identidade institucional, dos movimentos sociais e faz parte das ações dos docentes junto às comunidades, são ações "dentro da" e com as comunidades.

\section{Construindo a síntese: $O$ conhecimento social é emergente e gloca- lizado no contexto do controle internacional da ciência}

A nossa pesquisa nos leva a reiterar o que disse Afonso (2015) sobre os processos avaliativos - haveria um "vírus" na academia. A educação superior vem desenvolvendo estratégias de avaliação influenciadas por políticas de ressonância internacional que repercutem nas decisões sobre investimentos e organização institucional. Parece que a autonomia institucional das universidades foi substituída pela gestão estratégica com vistas ao desenvolvimento econômico, buscando sua sobrevivência. Muitas universidades passaram a se preocupar com rankings nacionais e internacionais, tendo em vista as políticas do Sinaes, avaliações da Capes em busca de recursos. Esses processos também estão a marcar relações entre sujeitos dentro das instituições. Instalou-se um vírus na academia face ao produtivismo exigido pelas avaliações classificatórias.

Como vimos nesse estudo, essas não são críticas infundadas, mas constatações. É preciso pensar a dimensão local na produção de uma cultura global. Para tanto, levantamos como alternativa pensar a produção de um conhecimento social como emergente no processo de glocalização, mesmo em tempos de globalização.

O que é um conhecimento Glocalizado? Seria servir a "dois senhores" ou tentar a sobrevivência? A 'glocalização' não é movimento contrário à globalização, é proveniente dela. Uma influencia a outra e juntas somam para a cultura mundial. A interação "global" e "local" valoriza o lugar, dentro de um contexto de internacionalização e homogeneização. É a dialética entre local e global para ser 'Glocal' - em interface com o sistema-mundo, sem perder a autenticidade de sua missão. Defendemos que a Glocalização horizontal define as ações desenvolvidas no ensino, pesquisa e extensão, que caracterizam práticas educativas de caráter contra-hegemônico às estratégias homogeneizadoras das avaliações. 
Ao estudarmos o conceito de 'Glocalização', vimos que esse conceito surgiu na década de 80 a partir de uma estratégia mercadológica de origem japonesa. A glocalização é um neologismo resultante da fusão dos termos globalização e localização, ou seja, valoriza as particularidades de cada local e sua cultura, sem deixar de expandi-la e nem se perder dentro deste processo globalizado e homogeneizado de criação de padrões. O termo Glocal vem da antropologia cultural e teria sido usado por Roland Robertson em 1995. Denomina a mistura de culturas globais modernas com as tradicionais e valoriza particularidades de cada local.

O conceito Glocal foi introduzido inicialmente com o objetivo de reconhecer o processo de uma cultura local e proteger a exclusão causada por movimentos da Globalização, isto é, respeitar as diferenças de cultura de um determinado lugar, sem deixar de expandir a origem da cultura evitando, assim, a sua homogeneização e protegendo a diversidade cultural. Como exemplo, citamos as experiências de alguns dentre os pesquisadores do PPGEdu/Unemat, um programa de pós-graduação de uma universidade pública estadual que trabalha no âmbito social com formação acadêmica, resguardando a identidade regional e histórica peculiar do seu contexto.

O conhecimento Glocal emerge do local para o global como ensinou Milton Santos (2006). Dito de outra forma, emerge de um saber local (SANTOS, 2004) e toma como pressuposto fundante o senso comum para ser analisado e (re)construído pela consciência científica e retorna ao domínio comum para transformações sociais, visando a melhoria do ser humano. Dito de outra forma, o conhecimento local é reconstruído pela ciência e volta para a sociedade com o fim de transformá-la. Esse é o conhecimento prudente para uma vida decente. Por excelência é inovador. É a popularização do conhecimento científico que emerge do senso comum e a ele retorna como uma transformação e inovação.

E por inovação entendemos como, publicado por Leite (2001, p.45-53), "como um processo descontínuo de ruptura com os paradigmas tradicionais vigentes na educação, no ensino-aprendizagem, ou uma transição paradigmática, em que ocorre uma reconfiguração de saberes e poderes". O conhecimento nessa perspectiva de inovação é algo vivo e provoca mudanças, está sempre em movimento em busca de transformação do real. Não se trata de um conhecimento verdadeiro que não está aberto a críticas, posto de verdades absolutas como metanarrativas, mas trata sim, de um conhecimento marcado pelo protagonismo das pessoas e suas participações, necessidades e interesses.

Esse é o conhecimento que defendemos e que deve ser construído na universidade e avaliado pelos órgãos de regulação. É o conhecimento social que se constrói na universidade com e para a sociedade, no espaço, no território das relações educativas com a atuação do docente, educador, pesquisador e com 
autoria e protagonismo dos estudantes. Para o docente isto significa inserção na teoria não como um diálogo morto, mas como forma de entender na prática o conhecimento vivo. A prática pedagógica constrói um conhecimento social, vivo, palpitante de significação do humano ao trabalhar com a ética das relações com sua instituição, com a moralidade, com os afetos, a estética e com sua capacidade cognitiva altamente estimulada. A pesquisa faz emergir este conhecimento da prática.

\section{Impossível Concluir... Abrimos o Debate}

Os nossos estudos e experiências acadêmicas confirmam os efeitos das avaliações para a emergência de uma identidade universitária no viés do modo de produção capitalista e para atender a expansão internacional da ciência. Neste estudo enfatizamos a contraposição à esta perspectiva, discutindo uma produção de conhecimento que serve a um projeto contra-hegemônico de universidade, ou seja, que está posto na contramão das pressões que afetam os docentes-pesquisadores. Não se trata de negar estas pressões, a busca de qualidade, a necessidade das avaliações regulatórias ou a importância dos rankings e dos processos de mobilidade, de internacionalização das universidades. Trata-se, isto sim, de fazer emergir e tirar do silêncio as ações e os conhecimentos produzidos que nem sempre estão relatados nas publicações, documentados nos currículos Lattes, nas redes de pesquisa dos investigadores. As ações captadas no mapeamento das produções e ações dos docentes mostram percepções e ações silenciadas nas avaliações existentes até o momento.

Tratava-se, então, de categorizar essas ações e procurar revelar os impactos, intelectuais, sociais, culturais e, mesmo os econômicos que estão a ocorrer, fruto das práticas pedagógicas e científicas dos docentes e seus orientandos. $\mathrm{Na}$ Unemat, estas ações de pesquisa e de ensino e de extensão acontecem em seus diferentes campi e estão mapeadas segundo os territórios em que ocorrem. Ou seja, nesse estudo procuramos contribuir para as construções coletivas da produção do conhecimento regional; contribuir para que nós mesmos, os pesquisadores, consigamos pensar sobre nosso fazer e saberes e, com isto, valorizar o que é local e regional, e defender um perfil de instituição com "identidades" e não uma "identidade" única de universidade para o país.

Voltando a Chaimovitch (2016), temos que mostrar o impacto do que já fizemos, a exemplo do que estamos tratando de mostrar neste texto. O impacto dos estudos que selecionamos - apenas o reduzido número - mostram que as 
ações trataram de economia solidária com as pessoas que precisam realizar economia para sobreviver; trataram de educação do campo com as pessoas que trabalham no campo e precisam da pedagogia da alternância para sobreviver e crescer; mostram a qualificação de professores de educação básica pública, sua titulação, em seu local de trabalho - o projeto que se desdobra desde 1992 atende a formação dos docentes respeitando seus tempos livres, tempos de férias com tempos de atividade nas escolas, alternando módulos, usando o recurso das redes - para atingir a titulação desejada e necessária a cada comunidade do interior do país; mostram a educação indígena e ribeirinha sendo praticada nos seus territórios e na própria universidade; mostram a diversidade de línguas praticadas e a necessidade de adaptação das habilidades dos docentes universitários a um universo plural e multilíngue, cultural e politicamente diverso daquele das culturas eruditas e teorizantes da instituição universidade tradicional.

Dentre os impactos, ressalta-se a produção de livros bilingues para cada uma das etnias, materiais de apoio pedagógico para a docência nas aldeias, cujo efeito nas aulas não é exatamente passível de medição, mas, é o recurso mais necessário que existe à aproximação entre culturas e à ampliação do conhecimento inédito, mostram a valorização da cultura regional dos ribeirinhos, vivenciando a infância e a educação das crianças pantaneiras.

De tal sorte que, respondendo às questões propostas inicialmente, nesse estudo evidenciamos que estamos na encruzilhada a construir um conhecimento Glocalizado como sobrevivência estratégica da universidade no mundo globalizado. Um conhecimento que produz impactos intelectuais porque transforma ideias para produzir outras ideias e ações, e resgata as mesmas através da pesquisa e da escrita de artigos. Tais ideias e ações, saberes e conhecimentos, fazem os estudantes universitários, os indígenas-estudantes, os ribeirinhos-alunos, os movimentos sociais do campo e da cidade se tornarem cidadãos do mundo em espaços locais de formação de gerações atuais e gerações futuras. São conhecimentos que produzem impacto social porque influenciam modos de ser e de agir nas comunidades tendo em vista diminuir a desigualdade, mesmo que seja a desigualdade na capacidade de comunicação de apenas uma criança de língua apiaka e uma outra de língua mundurucu. Se estes conhecimentos geram impacto econômico, se vão contribuir para criar empregos ou formar empresas, possivelmente a resposta seria negativa. No entanto, se entendermos estes conhecimentos na perspectiva da economia solidária, teremos impactos econômicos visíveis pois tais conhecimentos servem para entender as práticas possíveis de economia solidária e de gestão do agronegócio familiar. São saberes, talvez de senso comum e organizativo, de populações que vivem às margens do sistema capitalista financeiro e monetarista em que sobrevivemos. Por outro lado, tais saberes podem se transformar em conhecimentos com impacto sobre 
o meio ambiente na medida em que os agroecossistemas familiares e o desenvolvimento rural sustentável podem vir a substituir práticas antiecológicas por práticas de economia solidária, cooperativismo e sustentabilidade, que preservam os ecossistemas pantaneiros e amazônicos da região.

Deixamos aqui a nossa reflexão sobre os processos de avaliação da pós-graduação que precisam ser repensados e potencializados. Os conhecimentos emersos pelas ações da Universidade e seus pesquisadores estão a explicitar saberes tácitos, construídos ao longo dos tempos nas comunidades, conhecimentos úteis para viver no meio ambiente preservando-o. Porém, é nosso entender que, mesmo localizado e regional, o conhecimento será global, porque pode ser útil a populações de outros contextos e territórios do mundo. A sabedoria consiste em divulgar tais conhecimentos mostrando seus impactos e trabalhar por novas formas de avaliação que consigam captar o Conhecimento Social Emergente e Glocal.

\section{REFERÊNCIAS}

AFONSO, A. J. O vírus da (sobre) vivência académica. Revista A Página da Educação, n. 205, série II, verão 2015, pp. 32-33.

AKKARI, A. Internacionalização das Políticas Educacionais: transformações e desafios. Petrópolis, Vozes, 2011.

CHAIMOVICH, H. Avaliação e impactos da ciência brasileira. CNPq. Apresentação em ppt para SBPC. 5 de setembro de 2016. Disponível em: http://www.microbiologia. ufrj.br/portal/index.php/pt/destaques/informes/450-presidente-do-cnpq-apresenta-nova-proposta-de-avaliacao-de-projetos-em-ct-i. Acesso em: 20 jan. 2019.

DALE, R. Globalização e educação: demonstrando a existência de uma "cultura educacional mundial comum" ou localizando uma "agenda globalmente estruturada para a educação"? Educação e Sociedade. Campinas, vol. 25, n. 87, p. 423-460, maio/ago, 2004.

EDWARDS, M. A., \& ROY, S. Academic research in the 21st century: Maintaining scientific integrity in a climate of perverse incentives and hypercompetition. Environmental Engineering Science, 34(1), 51-61, 2017.

KRAWCKZIK, N; SANDOVAL, S. A. O Processo de Regionalização das Universidades do Mercosul: um estudo exploratório de regulação supranacional e nacional. Educação e Realidade. Porto Alegre, v. 37, n. 2, p. 647-668, maio/ago. 2012.

LEITE, D. Innovaciones en la educación universitária. In: CSE/Udelar. Primer Foro. Innovaciones educativas en la enseñanza de grado, 26/09/2001. Montevideo: CSE/ 
UDELAR AUGM, 2001. pp. 45-53.

LEITE, D; GENRO, M. E. H. Avaliação e internacionalização da educação superior: Quo vadis América Latina? Avaliação (Campinas). 2012, vol.17, n.3, pp.763-785.

LIMA, E. G. dos S.; MALANGE, F. C. V.; BARBOSA, V. A. B. Políticas de Expansão da Educação Superior Implantadas Pelo Estado Brasileiro: Reflexões Sobre Democratização: o caso da Unemat. In: CHAVES, V. L. J,; MAUÉS, O. C.; HAGE, S. M. Expansão privado-mercantil da educação superior no Brasil. Campinas, SP: Mercado de Letras, 2016.

LIMA, E. G. S.; LEITE, D.; et al. Projeto de pesquisa: Avaliação, regionalização e internacionalização da educação superior: ações na Unemat 2016-2018. Dissertação (Mestrado). Universidade do Estado de Mato Grosso. Cáceres, 2016.

MACHADO, I. F. Relação Trabalho-Educação Em Escolas do Campo. In: Livro da Anped-CO, Vol. I, 2012.

MALDONADO, M. M. C. Espaço pantaneiro: cenário de subjetivação da criança ribeirinha. Curitiba: CRV, 2017

MARGINSON, S., RHOADES, G. D. Beyond national states, markets, and systems of higher education: A glonacal agency heuristic. Higher Education. 2002; 43(3): 281-309.

MOROSINI, M. C. Internacionalização da Educação Superior. In: MOROSINI, M. C. (Ed) Enciclopédia de Pedagogia Universitaria. Vol. 2. Glossário. Brasília: Inep, 2006

ROBERTSON, R. Glocalization: time-space and homogeneity-heterogeneity. Chapter 2 (p. 25-43). In: Featherstone, Mike, Scott Lash, and Roland Robertson (Eds). Global Modernities. London: Sage Publications, pp. 25-44, 1995.

SANTOS, B. de S. (Org.). Conhecimento Prudente para uma vida decente: um discurso sobre as ciências revisitado. São Paulo, Cortez, 2004.

SANTOS, M. A Natureza do Espaço: Técnica e Tempo, Razão e Emoção. 4. ed. 2. reimpr. São Paulo: Editora da Universidade de São Paulo, 2006.

SGUAREZI, S. B.; DUARTE, W. M.; GAZONI, E. G. Práticas agroecológicas dos empreendimentos econômicos solidários (EES) da comunidade Chê Guevara no Assentamento Antônio Conselheiro - Tangará da Serra-MT. In: ZART, L. L; VAILANT, Clovis (Org.). Educação e socioeconomia solidária: configurações do campo e experiências educacionais. Série sociedade solidária. Cáceres: Unemat, 2015, v. 7, p. 98-104.

ZART. L. L.; BITENCOURT, L. P. O processo de construção de conhecimentos: o diálogo entre a universidade e os movimentos sociais do campo na experiência do CAMOSC. In: ZART. L. L.; VAILANT, C. (Org.). Configurações do Campo e Experiências Educacionais. 1ed. Editora UNEMAT, 2015, v. 1, p. 127-133.

ZOIA, A.; ARAUJO, A. E. Mebêngõkre Kabêm: Língua do povo do buraco da água. 1. ed. Sinop: Gráfica Dados, 2018. v. 200. 60p. 
. Mini Dicionário Terena MT. 1. ed. Sinop: Gráfica Dados, 2018. v. 200.

$71 \mathrm{p}$.

ZOIA, A.; FERREIRA, W. A. A. Dicionário Ilustrado Apiaká. 1. ed. Sinop: Gráfica Dados, 2018. v. 200. 68p.

Cartilha Kawaiwete. 1. ed. Sinop: Gráfica Dados, 2018. v. 200. 54p.

ZOIA, A.; NASCIMENTO, R.; FERREIRA, W. A. A. Saberes Indigenas na Escola: Frutas Silvestres. 1. ed. Sinop: Gráfica Dados, 2018. v. 200. 70p.

Texto recebido em 12 de abril de 2019.

Texto aprovado em 01 de maio de 2019. 